\title{
Tolerability of an Immunologically Enhanced Subcutaneous Immunotherapy Preparation in Patients Treated with Concomitant Allergy Immunotherapy: A Non-Interventional Observational Study
}

\author{
Rainer Reiber $^{1} \cdot$ Hendrik Wolf $^{2}$ (1) Jörg Schnitker $^{3} \cdot$ Eike Wüstenberg $^{2,4}$
}

Published online: 9 January 2017

(c) The Author(s) 2017. This article is published with open access at Springerlink.com

\begin{abstract}
Background For causal treatment by allergy immunotherapy (AIT) a single or few allergen products for the clinically most relevant allergens are applied to treat multiple allergies, but few data on the tolerability of multiple AIT applications are available.

Objective The aim of our study was to investigate safety and tolerability in patients treated by subcutaneous immunotherapy (SCIT) and concomitant SCIT or sublingual immunotherapy (SLIT) products.

Methods In a non-interventional, observational study in Germany treatment of patients with a primary SCIT and concomitant AIT (SCIT or SLIT) was documented during the first 4 months of treatment. Adverse events (AEs) were recorded by the physicians and by patients in diaries, and coded using the Medical Dictionary for Regulatory Activities (MedDRA).

Results Three hundred and seven patients were treated with the primary SCIT by 79 allergists, and 271 received a concomitant AIT. AEs were reported in 92 (33.9\%) patients and adverse drug reactions (ADRs) in 63 (23.2\%) patients related to the primary SCIT and in 69 $(25.5 \%)$ to the concomitant AIT; six $(2.2 \%)$ patients
\end{abstract}

Hendrik Wolf

hendrik.wolf@alk.net

HNO-Praxis, 73614 Schorndorf, Germany

2 ALK-Abelló Arzneimittel GmbH, Clinical Development/ Medical Department, Griegstrasse 75, Haus 25, 22763 Hamburg, Germany

3 Institut für angewandte Statistik Dr. Jörg Schnitker GmbH, 33602 Bielefeld, Germany

4 Universitätsklinikum Carl Gustav Carus, Clinic for Otolaryngology, 01307 Dresden, Germany discontinued due to ADRs. ADRs were mild or moderate in $40(14.8 \%)$ patients, severe in $23(8.5 \%)$, and serious in one patient. The most frequent reactions were local swelling and pruritus. Overall tolerability was assessed as 'good' or 'very good' by $95.6 \%$ of patients and $96.7 \%$ of physicians.

Conclusions Compared with data from a large previous study no increase in the frequency of ADRs in real life or change in the tolerability profile was observed for SCIT with concomitant SCIT or SLIT.

\section{Key Points}

Tolerability of subcutaneous allergy immunotherapy was not affected if applied with concomitant allergy immunotherapy products.

Treatment with more than one product appears not to impair overall safety and tolerability.

\section{Introduction}

A high proportion of allergic patients with respiratory allergy and manifesting as allergic rhinoconjunctivitis with or without allergic asthma are poly-sensitized in accordance with the spectrum of allergens patients are exposed to in their geographical region [1].

For poly-sensitized patients who suffer from more than one essential clinically relevant allergy adequate treatment with specific immunotherapy is challenging. The approaches for allergy immunotherapy are different in Europe and 
the USA. The European approach is that allergy immunotherapy (AIT) products containing single allergens are used and one or a few different allergen products are applied to treat the clinically most important seasonal and/ or perennial allergies $[2,3]$.

The majority of patients treated by AIT in Germany are given subcutaneous injections, but sublingual immunotherapy (SLIT) as liquid formulations or tablets, currently available with grass and house dust mite allergens, are being used more and more often. Only a few reports on systematically recorded data for tolerability of simultaneous application of more than one AIT product are currently available [4]. The tolerability of treatment with the $\mathrm{SQ}^{\circledR}$ grass SLIT-tablet when applied with concomitant AIT has been investigated in a separate study. No change in the tolerability profile and frequency of reactions with the $\mathrm{SQ}^{\circledR}$ grass SLIT-tablet has been observed [5].

The aim of the present study was to investigate whether tolerability of treatment with an immunologically enhanced subcutaneous immunotherapy (SCIT) product $\left(\mathrm{AVANZ}^{\circledR}\right.$ ) is influenced when applied with concomitant AIT in the real-life setting. The SCIT product primarily applied in this study was a short up-dosed (by five injections) immunologically enhanced formulation with an optimized allergen to aluminium hydroxide ratio allowing the administration of lower doses for maintenance treatment. This treatment has been shown to induce similar immunological effects [6-8] to the traditional SCIT product of the same $\mathrm{SQ}^{\circledR}$ standardized composition with a longer up-dosing period and a higher allergen concentration for maintenance treatment (Alutard $\mathrm{SQ}^{\circledR} / \mathrm{ALK}$-depot $\mathrm{SQ}^{\circledR}$ ). In a multicentre phase II/III trial in Spain with the immunologically enhanced SCIT product (AVANZ ${ }^{\circledR}$ Phleum) it was found that the total number of adverse drug reactions (ADRs) was associated with the number of grass allergens to which the patients were sensitized [9].

\section{Methods}

\subsection{Study Design}

This study was multicentre, open, uncontrolled, and observational according to non-interventional post-authorization surveillance studies mentioned in the German drug law for recording of data concerning tolerability and routine application of drugs after marketing authorization. These studies are explicitly excluded from the application of EU guidelines on clinical trials [10] and are, thus, not conducted according to Good Clinical Practice (GCP) guidelines [11].

All patients included were treated with the immunologically enhanced SCIT product (AVANZ ${ }^{\circledR}$, ALK-Abelló,
Denmark) following the specifications for administration in the summary of product characteristics (SmPC) [12]. Data were analysed by epidemiological methods. Centres were distributed all over Germany and were asked to record data on patients in a consecutive order dependent on the patient's willingness to participate in the study in order to avoid a selection bias.

Documentation was started at first administration of the primary SCIT (visit 1). Subsequently, all further SCIT injections were entered in an injection protocol and any adverse events (AEs) due to the SCIT and/or the concomitant AIT were recorded up to a total observation period of about 4 months. Documentation was completed at a second visit (V2) at the end of the observation period. A diagrammatic outline of the study is shown in Fig. 1.

\subsection{Allergy Immunotherapy}

All patients included in the study received treatment with the immunologically enhanced SCIT product AVANZ ${ }^{\circledR}$ (ALK, Denmark) using one of the following allergens: tree mix (hazel/alder/birch), birch, grass mix and rye (Dactylis

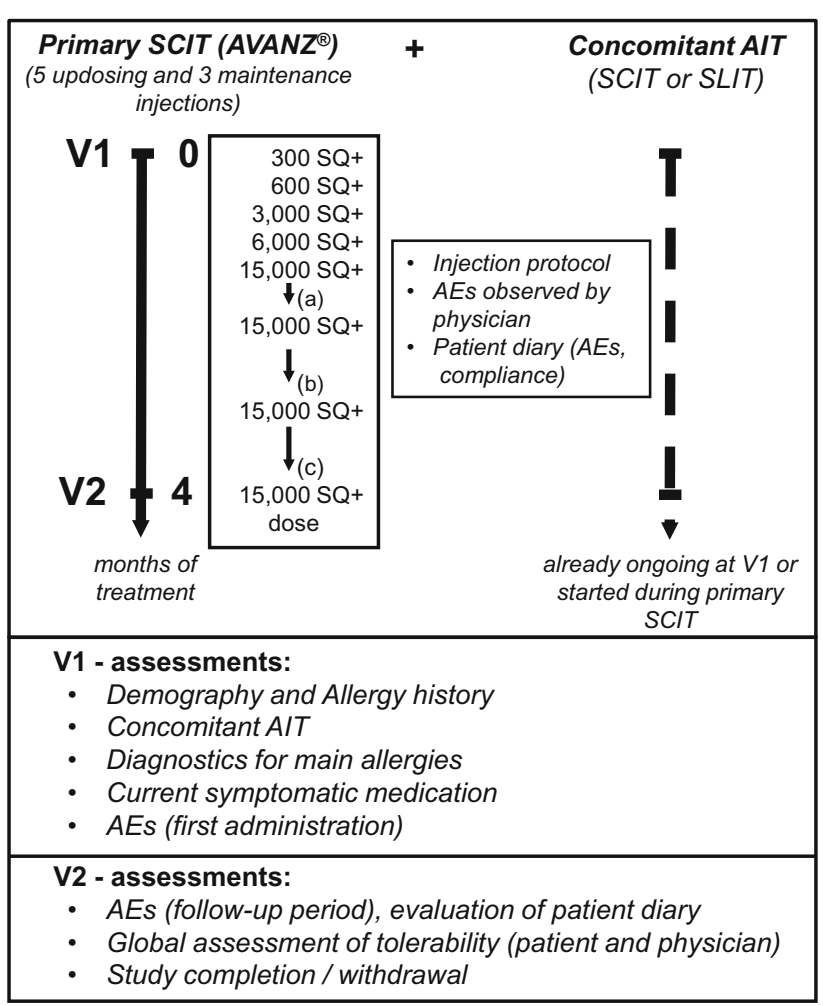

Fig. 1 Diagrammatic representation of the study. Primary SCIT $\left(\mathrm{AVANZ}^{\circledR}\right)$ was up-dosed according to the summary of product characteristics with five injections in weekly intervals and when the maintenance dose was reached the injection interval was increased stepwise by 2 weeks $(a)$ to an injection interval of $6 \pm 2$ weeks (b) and (c). SCIT subcutaneous immunotherapy 
glomerata/Festuca pratensis/Lolium perenne/Phleum pratense/Secale cereale), Phleum pratense, mugwort, mite mix (Dermatophagoides pteronyssinus/Dermatophagoides farinae) or Alternaria alternata as primary AIT.

Treatment was initiated between September 2012 and January 2014. According to the SmPC of AVANZ ${ }^{\circledR}$ [12], SCIT is initiated by a five-step up-dosing schedule (300, $600,3,000,6,000,15,000 \mathrm{SQ}+$ ) with injection intervals of 1 week. When the maintenance dose has been reached the injection interval is increased stepwise by 2 weeks to an injection interval of $6 \pm 2$ weeks (Fig. 1).

\subsection{Ethics, Consent and Permissions}

According to German drug law, non-interventional postmarketing studies have to be notified to the authorities. The study was approved by the Ethics Committee of the Landesärztekammer Baden-Württemberg (Reference No. F-2012-043) and consent from the patients for collection of their data was obtained. The decision by the physician to prescribe SCIT as primary AIT and concomitant AIT was taken independently from the inclusion of the patient in the study. For recording and evaluation of data, patients were assigned a three-digit patient number. Direct identification of the patients was restricted to the physicians' offices that participated in the study.

\subsection{Patients}

In the study 307 patients were included by 79 allergists distributed around Germany. Adult patients ( $\geq 18$ years) with a diagnosis of rhinitis and/or conjunctivitis (according to symptoms, skin prick test or specific IgE measurement) with or without asthma with clinically relevant symptoms that were treated with $\mathrm{AVANZ}^{\circledR}$ and a concomitant AIT (SCIT or SLIT) who had no contraindications to a prescription according to the SmPC of AVANZ ${ }^{\circledR}$ [12] were eligible to be documented in this study.

Indications according to the SmPC are: treatment of allergic rhinoconjunctivitis in patients with allergy with or without mild to moderate asthma. Contraindications were: immunopathological conditions such as immune complex and immunodeficiency diseases and autoimmune diseases, diseases or conditions preventing the treatment of possible anaphylactic reactions, e.g. chronic heart and lung diseases, severe arterial hypertension and treatment with $\beta$-receptorblockers, malignancies, renal dysfunction/impairment, uncontrolled or severe asthma (in adults: $\mathrm{FEV}_{1}<70 \%$ of predicted value after adequate pharmacological treatment, in children: a $\mathrm{FEV}_{1}<80 \%$ of predicted value after adequate pharmacological treatment), and known hypersensitivity to any of the excipients.

\subsection{Assessments}

The time schedule and the major assessments of the study are shown in Fig. 1.

Upon inclusion of the patient at visit 1 (V1) demographic data and data on the allergy history including age at first appearance of symptoms, clinical manifestation of the allergy (rhinitis/conjunctivitis/asthma/atopic dermatitis), other allergies, the diagnostics performed, any previous AIT, and concomitant treatments by AIT or other medications due to concomitant diseases were recorded. The currently used anti-allergic medication was recorded (topical or oral antihistamines, nasal or oral corticosteroids, inhaled corticosteroids, inhaled short-acting $\beta_{2}$ agonists (SABAs), inhaled long-acting $\beta_{2}$ agonists (LABAs), and other as specified).

The administration of any AIT was documented in the case report form (CRF) by injection protocols of the primary SCIT and, if applicable, of a concomitant SCIT or by recording the first application of a concomitant SLIT. The administration of the AIT was completely recorded in patient diaries including the primary SCIT and all concomitant AITs (SCIT and/or SLIT), if applicable.

During administration of AIT tolerability was assessed based on AEs recorded by the physician at administration in the office and by the patient in the diary. An AE was defined as any untoward medical occurrence in a patient who was treated with any AIT (primary or concomitant) and which did not necessarily have a causal relationship with treatment. AEs that were possibly related to treatment were classified as ADRs of the primary SCIT or the concomitant AIT, respectively. When side effects occurred during home treatment patients were instructed to record the symptoms, the time of last administration of AIT and the time of occurrence of the side effect, the severity (mild, moderate or severe) and the actions taken due to the side effects (no action, taking a medication-if yes, which product and due to which symptoms?, visit to the doctor, discontinuation of treatment, something else-if yes, what?).

AEs were specified by the physician in the CRF as diagnosis or description and assessed by severity (mild, moderate or severe), causality (possible or unlikely), change of treatment (no change, interruption or discontinuation), treatment with medication (yes, no), outcome (recovered, recovered with sequelae, not recovered, fatal or unknown) and seriousness (yes, no). An AE was assessed as severe when the event considerably interfered with the patient's daily activities. A serious AE (SAE) was defined as any medical occurrence or effect that was life-threatening, required hospitalization or prolongation of hospitalization, resulted in persistent or significant disability or 
incapacity, resulted in death, congenital abnormalities or birth defect, or any other event judged medically important.

After about 4 months of treatment the documentation for the study was completed with a final visit (V2). At V2 the physician interviewed the patients with respect to side effects that occurred between V1 and V2, i.e. during home treatment with SLIT, if applicable, and recorded all AEs in the CRF together with his medical assessment.

In addition, an overall assessment of tolerability (very good, good, moderate or poor) was performed by patients and physicians at $\mathrm{V} 2$, and the continuation or discontinuation of treatment and its reasons were recorded.

SAEs were further documented on a separate report form, and if applicable according to legal pharmacovigilance procedures, they were reported to the authorities.

\subsection{Statistics}

Data analysis was performed solely by descriptive statistics using minimum, maximum, median, mean, range and standard deviation for continuous data as well as frequency distributions for ordinal data. No imputation was performed in case of missing data, but all available data were used to their full extent. The principal statistical software used was $\mathrm{SAS}^{\circledR}$, version 9.3.0.

No formal sample size calculation has been made for this study. The primary objective was to record data on safety and tolerability of the primary SCIT when applied with concomitant AIT. In order to obtain a real-life picture the study aimed to engage a large number of physicians in the study who recorded data on patients who were routinely treated with the primary SCIT and concomitant AIT. AEs were coded according to the current version of the Medical Dictionary for Regulatory Activities (MedDRA). ADRs were displayed for patients and according to the level of events including multiple occurrences by patient.

\section{Results}

\subsection{Patients}

The study was initiated in September 2012 and the last patient completed the study in April 2014. Patient characteristics and treatment with AIT are displayed in Table 1.

Treatment with the primary SCIT was recorded in 307 patients by 79 allergists. Treatment was discontinued in a total of $23(7.5 \%)$ patients, eight $(2.6 \%)$ patients did not return after the first injection of the primary SCIT, ten (3.3\%) patients discontinued due to AEs, two $(0.7 \%)$ patients discontinued due to non-compliance, two $(0.7 \%)$ patients withdrew their consent and one $(0.3 \%)$ patient moved. Treatment with the primary SCIT was continued at the end of the observation period in 284 (92.5\%) patients.

\subsection{Treatment by AIT}

It was intended that only data from patients who were concomitantly treated with another AIT were recorded. In 36 patients, however, no concomitant AIT had been applied. Therefore, the tolerability data are presented separately for patients with concomitant AIT $(N=271)$, patients without concomitant $\operatorname{AIT}(N=36)$ and total patients $(N=307)$.

The majority of patients included in the study were treated by one concomitant SCIT (69.4\%), $26.9 \%$ of patients received one concomitant SLIT (SLIT-tablet $21.0 \%$, SLIT-drops $5.9 \%$ ) and $3.7 \%$ of patients received two concomitant AIT products (SCIT + SLIT 3.0\% and SCIT + SCIT 0.7\%). Tree pollen allergens were applied as primary SCIT in $146(53.9 \%)$ patients, grass pollen allergens in $66(24.4 \%)$ and house dust mite allergens in 51 (18.8\%) patients (mugwort: seven $(2.6 \%)$ patients, $A l$ ternaria alternata: one $(0.4 \%)$ patient). The different allergens used for treatment of patients as primary SCIT and concomitant AIT (SCIT / SLIT) are shown in Table 2. The most frequent allergens applied as concomitant AIT were grass pollen, house dust mites and tree pollen. Concomitant treatment was started in 231 (86.8\%) patients before and at initiation of the primary SCIT, respectively, and in $35(13.2 \%)$ patients after the initiation of the primary SCIT.

\subsection{Tolerability}

A summary of all AEs and ADRs related to the primary SCIT reported during the observation period is shown in Table 3. The ADR rates were very similar in the group of patients with concomitant AIT $(23.2 \%)$ and in the group without concomitant AIT (22.2\%). In 40/271 (14.8\%) patients treated with the primary SCIT and concomitant AIT, severity of ADRs to the primary SCIT was assessed mild or moderate and assessed as severe in 23/271 (8.5\%) patients. Treatment with the primary SCIT was discontinued due to ADRs in six (2.2\%) patients with concomitant AIT and in eight $(2.6 \%)$ patients of all the patients included. The ADR rate was the same in adult patients and patients $<18$ years of age $(23.1 \%)$. In patients with a history of AIT the ADR rate was higher $(36.7 \%)$ than in patients without AIT in their history $(20.3 \%)$. ADRs related to the concomitant AIT, concomitant SCIT and concomitant SLIT are shown in Table 4. No relevant differences were observed for the rates of ADRs for patients treated with concomitant SCIT, concomitant SLIT and SCIT/SLIT 
Table 1 Patient characteristics

\begin{tabular}{|c|c|c|c|}
\hline & $\begin{array}{l}\text { Primary SCIT and } \\
\text { concomitant AIT }\end{array}$ & $\begin{array}{l}\text { Primary SCIT, no } \\
\text { concomitant AIT }\end{array}$ & $\begin{array}{l}\text { All patients treated } \\
\text { with primary SCIT }\end{array}$ \\
\hline Patients, $n$ & 271 & 36 & 307 \\
\hline Age, years \pm SD & $36.5 \pm 13.9$ & $38.9 \pm 12.9$ & $36.8 \pm 13.8$ \\
\hline Patients 5-11 years, $n(\%)$ & $5(1.8)$ & - & $5(1.6)$ \\
\hline Patients $12-17$ years, $n(\%)$ & $8(3.0)$ & - & $8(2.6)$ \\
\hline Patients $\geq 18$ years, $n(\%)$ & $258(95.2)$ & $36(100.0)$ & $294(95.8)$ \\
\hline \multicolumn{4}{|l|}{ Gender, $n(\%)$} \\
\hline Male & $129(47.6)$ & $12(33.3)$ & $141(45.9)$ \\
\hline Female & $142(52.4)$ & $24(66.7)$ & $166(54.1)$ \\
\hline $\begin{array}{l}\text { Age at first diagnosis of allergy, } \\
\text { years }( \pm \mathrm{SD})\end{array}$ & $30.4( \pm 14.4)$ & $36.7( \pm 13.3)$ & $31.1( \pm 14.4)$ \\
\hline \multicolumn{4}{|l|}{ Major manifestations, $n(\%)$} \\
\hline Rhinitis & $258(95.2)$ & $34(94.4)$ & $292(95.1)$ \\
\hline Conjunctivitis & $184(67.9)$ & $27(75.0)$ & $211(68.7)$ \\
\hline Asthma & $81(29.9)$ & $4(11.1)$ & $85(27.7)$ \\
\hline Atopic dermatitis & $25(9.2)$ & $3(8.3)$ & $28(9.1)$ \\
\hline $\begin{array}{l}\text { Concomitant allergies not treated in this } \\
\text { study, } n(\%)\end{array}$ & $165(60.9)$ & $19(52.8)$ & $184(59.9)$ \\
\hline History of AIT, $n(\%)$ & $49(18.1)$ & $4(11.1)$ & $53(17.3)$ \\
\hline
\end{tabular}

$A I T$ allergy immunotherapy, SCIT subcutaneous immunotherapy, SD standard deviation

combinations. ADRs related to the primary SCIT, concomitant AIT, concomitant SCIT and concomitant SLIT reported in two or more patients are displayed as MedDRA System Organ Classes (SOCs) and Preferred Terms (PTs) in Table 5. Most frequent reactions ( $\geq 5 \%$ of patients) assessed related to SCIT were pruritus (primary SCIT: $7.4 \%$ of patients, concomitant SCIT: $7.6 \%$ ) and local swelling (primary SCIT: $5.9 \%$, concomitant SCIT: $7.6 \%$ ). Most frequent reactions assessed related to the concomitant SLIT were throat irritation $(8.6 \%)$, oral pruritus $(6.2 \%)$ and ear pruritus (6.2\%). Serious AEs were reported in two patients. A 34-year-old male patient treated with SCIT with tree and grass pollen allergens $\left(\mathrm{AVANZ}^{\circledR}\right.$ tree mix and AVANZ $^{\circledR}$ grass mix and rye) was hospitalized due to pertussis. The event was assessed as being unlikely to be related to AIT. In a 52-year-old female patient with medical history of allergy to grass pollen, birch pollen and house dust mites and symptoms of allergic rhinitis and bronchial asthma, an AE was classified serious and assessed as possibly related to treatment with the SCIT (AVANZ $^{\circledR}$ Phleum pratense and AVANZ ${ }^{\circledR}$ mite mix, updosing injection no. 4, dose $3.000 \mathrm{SQ}+$ for both products, interval between injections $30 \mathrm{~min}$ ) and concomitant SLIT $\left(\right.$ STALORAL birch ${ }^{\circledR}$ ). Both injections had been applied before onset of the SAE symptoms, and the time of SLIT administration was not documented. In this patient a severe systemic reaction with eyelid swelling, rough voice and shortness of breath was reported and considered medically important. The patient was treated for her asthma with a combination of inhaled corticosteroids and beta-agonists (fluticasone propionate and salmeterol). She recovered after intravenous administration of corticosteroids, antihistamine and a volume substitute $(\mathrm{NaCl})$ on the same day. Due to the intravenous administration of steroids the event was upgraded from a systemic reaction to an anaphylactic reaction. AIT with both SCIT products was discontinued.

Overall tolerability in our study was assessed as 'good' or 'very good' by $95.6 \%$ of patients and $96.7 \%$ of physicians.

\subsection{Compliance}

Patient diaries could be evaluated in 239 (78.6\%) of the 307 patients included in the study (three missing values) and in $217(80.4 \%)$ of the 271 patients (one missing value) with a concomitant AIT. In 67 out of 81 patients who received a concomitant SLIT (including eight patients with SCIT and SLIT combinations) diary records could be analysed that resulted in compliance rates with SLIT of $\geq 80 \%$ in $40(59.7 \%)$ patients, $50-79 \%$ in six $(9.0 \%)$ and $<50 \%$ in $21(31.3 \%)$ patients. In $254(94.1 \%)$ out of the 271 patients with primary SCIT and concomitant AIT (one missing value) the patient performed the AITs as instructed, but not in a further 16 (5.9\%) patients (appointments not kept for injections: 12 patients; discontinued: one patient; other reasons: three patients) according to the physician's assessment. 
Table 2 Treatment of patients with primary SCIT and concomitant AIT (SCIT, SLIT)

\begin{tabular}{|c|c|c|}
\hline Patients with primary SCIT and concomitant AIT & $n$ & $\%$ \\
\hline Primary SCIT (AVANZ $\left.{ }^{\circledR}\right)$ & 271 & 100.0 \\
\hline Tree mix & 102 & 37.6 \\
\hline Birch & 44 & 16.2 \\
\hline Grass mix and rye & 60 & 22.1 \\
\hline Phleum pratense & 6 & 2.2 \\
\hline House dust mite mix & 51 & 18.8 \\
\hline Mugwort & 7 & 2.6 \\
\hline Alternaria alternata & 1 & 0.4 \\
\hline One concomitant SCIT & 188 & 69.4 \\
\hline Grasses and rye & 64 & 23.6 \\
\hline House dust mites & 59 & 21.8 \\
\hline Trees (hazel/alder/birch) & $46^{\mathrm{a}}$ & 17.0 \\
\hline Weed pollen & 6 & 2.2 \\
\hline Grasses and rye/trees & 5 & 1.8 \\
\hline Grasses and rye/weed pollen & 3 & 1.1 \\
\hline Moulds & 3 & 1.1 \\
\hline Animal epithelia & 1 & 0.4 \\
\hline Wasp venom & 1 & 0.4 \\
\hline One concomitant SLIT & 73 & 26.9 \\
\hline Concomitant SLIT-tablet (grass) & 57 & 21.0 \\
\hline Concomitant SLIT-drops & 16 & 5.9 \\
\hline Trees & 7 & 2.6 \\
\hline House dust mites & 7 & 2.6 \\
\hline Animal epithelia & 1 & 0.4 \\
\hline Weed pollen & 1 & 0.4 \\
\hline Concomitant SCIT + SLIT-drops & 4 & 1.5 \\
\hline Grass + tree & 2 & 0.7 \\
\hline Tree + house dust mites & 2 & 0.7 \\
\hline Concomitant SCIT + SLIT-tablet & 4 & 1.5 \\
\hline House dust mites + grass tablet & 3 & 1.1 \\
\hline Oak pollen + grass tablet & 1 & 0.4 \\
\hline Concomitant SCIT + SCIT & 2 & 0.7 \\
\hline Grass + house dust mites & 1 & 0.4 \\
\hline Trees + moulds & 1 & 0.4 \\
\hline
\end{tabular}

AIT allergy immunotherapy, SCIT subcutaneous immunotherapy, SLIT sublingual immunotherapy

${ }^{\text {a }}$ Including one patient treated with oak pollen

\section{Discussion}

In this study investigating tolerability in 271 patients treated concomitantly with more than one AIT product, SCIT as primary treatment and SCIT or SLIT as concomitant treatment, patients most frequently received one concomitant SCIT $(69.4 \%)$, less frequently one concomitant SLIT (26.9\%) and only in rare cases two concomitant AITs $(3.7 \%)$ as combinations of SCIT and SLIT or two
SCIT products. Tree pollen (53.9\%), grass pollen $(24.4 \%)$ and house dust mite allergens $(18.8 \%)$ were predominantly applied as primary SCIT, and grass, house dust mite and tree allergen products as concomitant AIT. AEs were observed in $33.9 \%$ of 271 patients with primary SCIT and concomitant AIT, and AEs assessed possibly related (ADRs) to the primary SCIT in $23.2 \%$ of patients and to the concomitant AIT in $25.5 \%$ (SCIT: $25.3 \%$, SLIT: $28.4 \%$ ). The most frequent reactions ( $\geq 5 \%$ of patients) were pruritus and local swelling for treatment by SCIT and throat irritation, oral pruritus and ear pruritus for treatment by SLIT. ADRs to the primary SCIT were of mild to moderate severity (14.8\%) in the majority of all patients with primary SCIT and concomitant AIT and less frequently severe $(8.5 \%)$. A systemic reaction in one patient who suffered from allergic rhinoconjunctivitis and bronchial asthma treated with two SCIT products (house dust mite, timothy grass) and one SLIT product (birch) with eyelid swelling, rough voice and shortness of breath was assessed as medically important and, thus, classified as serious; due to the application of intravenous corticosteroids the case was upgraded to MedDRA PT anaphylactic reaction. Treatment was discontinued due to ADRs in $2.2 \%$ of patients who received the primary SCIT and concomitant AIT.

The available safety data on treatment with more than one allergen extract in patients with multiple allergies have been reviewed by Passalaqua et al. [2] and Calderon et al. [3]. The tolerability of a SCIT treatment by one single allergen extract or two allergen extracts applied in parallel has been investigated in a retrospective study including 147 patients who received injections with pollen, house dust mite, mould, animal dander or hymenoptera venom allergens. The rate of ADRs during the dose increase phase was observed to be slightly higher in the group of patients that had been treated by two injections given in parallel without being significant [4].

Tolerability data have been recorded in a previous noninterventional observational study in 1036 patients treated with the same product as that applied as primary SCIT in our study $\left(\mathrm{AVANZ}^{\circledR}\right)$, predominantly using tree pollen, grass pollen and house dust mite allergens during a 1-year observation period; the proportion of patients who received a concomitant AIT was $16 \%$ in that study [13], thus indicating that the proportion of patients who are treated by more than one AIT product in parallel in Germany appears to be small. The proportion of patients with ADRs in our study $(24.5 \%)$ was not very different compared with the previous study (20.8\%), whereas the severity of ADRs was classified in more patients as severe $(8.5 \%)$ compared with the data from the previous study $(2.9 \%)$, possibly indicating a higher severity of ADRs when more than one AIT product is applied, but comparison of data between the two 
Table 3 Summary of patients with AEs and ADRs related to the primary SCIT

\begin{tabular}{llll}
\hline & $\begin{array}{l}\text { Primary SCIT and } \\
\text { concomitant AIT } \\
n(\%), \mathrm{E}\end{array}$ & $\begin{array}{l}\text { Primary SCIT, } \\
\text { no concomitant AIT } \\
n(\%), \mathrm{E}\end{array}$ & $\begin{array}{l}\text { All patients treated } \\
\text { with primary SCIT } \\
(\%), \mathrm{E}\end{array}$ \\
\hline Patients & 271 & 36 & 307 \\
AEs, total & $92(33.9), 727$ & $10(27.8), 71$ & $102(33.2), 798$ \\
Primary SCIT discontinued & $8(3.0), 21$ & $2(5.6), 13$ & $10(3.3), 34$ \\
ADRs, possibly related to AVANZ & $63(23.2), 441$ & $8(22.2), 64(23.1), 505$ \\
Treated by medication & $26(9.6), 147$ & $6(16.7), 19$ & $32(10.4), 166$ \\
Severity: mild & $16(5.9), 196$ &,- 15 & $16(5.2), 211$ \\
$\quad$ Moderate & $24(8.9), 146$ & $1(2.8), 26$ & $25(8.1), 172$ \\
$\quad$ Severe & $23(8.5), 94$ & $7(19.4), 23$ & $30(9.8), 117$ \\
$\quad$ Missing value &,- 5 & - &,- 5 \\
Serious & $1(0.4), 4$ & - & $1(0.3), 4$ \\
Primary SCIT discontinued & $6(2.2), 19$ & $2(5.6), 11$ & $8(2.6), 30$ \\
\hline
\end{tabular}

$A E$ adverse event, $A D R$ adverse drug reaction, AIT allergy immunotherapy, E number of events, SCIT subcutaneous immunotherapy, SLIT sublingual immunotherapy

Table 4 Patients with ADRs related to the concomitant AIT

\begin{tabular}{llll}
\hline & $\begin{array}{l}\text { Concomitant AIT } \\
n(\%), \mathrm{E}\end{array}$ & $\begin{array}{l}\text { Concomitant SCIT } \\
n(\%), \mathrm{E}\end{array}$ & $\begin{array}{l}\text { Concomitant SLIT } \\
n(\%), \mathrm{E}\end{array}$ \\
\hline Patients & 271 & $198^{\mathrm{a}}$ & $81^{\mathrm{a}}$ \\
ADRs, possibly related to concomitant AIT & $69(25.5), 534$ & $50(25.3), 361$ & $23(28.4), 232$ \\
$\quad$ Treated by medication & $29(10.7), 141$ & $22(11.1), 86$ & $9(11.1), 65$ \\
Severity: mild & $17(6.3), 271$ & $12(6.1), 185$ & $6(7.4), 119$ \\
$\quad$ Moderate & $29(10.7), 177$ & $19(9.6), 112$ & $10(12.3), 77$ \\
$\quad$ Severe & $23(8.5), 84$ & $19(9.6), 62$ & $7(8.6), 36$ \\
$\quad-, 2$ &,- 2 & - \\
Missing value & $1(0.4), 4$ & $1(0.5), 4$ & $1(1.2), 4$ \\
Primarious & $5(1.8), 15$ & $4(2.0), 13$ & $4(4.9), 14$
\end{tabular}

$\overline{A D R}$ adverse drug reaction, AIT allergy immunotherapy, $E$ number of events, SCIT subcutaneous immunotherapy, SLIT sublingual immunotherapy

${ }^{a}$ Including eight patients with combinations of SCIT and SLIT

different studies must be interpreted with caution due to the different study periods and possible differences in the patient populations included, such as sensitization patterns, amongst others [9]. The proportion of patients (28.4\%) with ADRs in the group of patients treated with concomitant SLIT in our study was observed to be slightly higher than the proportion of patients $(25.3 \%)$ treated with concomitant SCIT. The observation period of our study included the up-dosing period by five injections and three maintenance injections with the primary SCIT product because ADRs are expected to occur with the highest frequency during the initial phase of SCIT treatment. Reflecting the general use of AIT in Germany, the majority of patients were treated with the primary SCIT and one concomitant SCIT product, fewer patients with a single concomitant SLIT product and only in rare cases with more than one concomitant AIT product.

In a study with a similar design investigating the tolerability of the $\mathrm{SQ}^{\circledR}$ grass SLIT-tablet applied with concomitant AIT, no change in the tolerability profile or increase in the frequency of adverse reactions compared with previous studies with the same product have been observed [5]. No concomitant AIT treatment has been recorded in $11.7 \%$ of patients treated with the primary SCIT. The data for this subgroup are displayed separately.

The open-label, uncontrolled, observational design of our study performed in real life has its limitations. Physician's practices that were distributed all over Germany participated in the study to minimize a potential 
Table 5 ADRs related to primary and concomitant AIT in $\geq 2$ patients in any treatment group

\begin{tabular}{|c|c|c|c|c|}
\hline $\begin{array}{l}\text { MedDRA system organ class } \\
\text { MedDRA preferred term }\end{array}$ & $\begin{array}{l}\text { Primary SCIT } \\
n(\%), \mathrm{E}\end{array}$ & $\begin{array}{l}\text { Concomitant SCIT } \\
n(\%), \mathrm{E}\end{array}$ & $\begin{array}{l}\text { Concomitant SLIT } \\
n(\%), \mathrm{E}\end{array}$ & $\begin{array}{l}\text { Concomitant AIT } \\
n(\%), \mathrm{E}\end{array}$ \\
\hline Patients, $n$ & 271 & $198^{\mathrm{a}}$ & $81^{\mathrm{a}}$ & 271 \\
\hline Patients with ADRs & 63 (23.2), 441 & $50(25.3), 361$ & $23(28.4 \%), 232$ & 69 (25.5), 534 \\
\hline Ear and labyrinth disorders & $2(0.7), 4$ & - & $5(6.2), 13$ & $5(1.8), 13$ \\
\hline Ear pruritus & $1(0.4), 1$ & - & $5(6.2), 13$ & $5(1.8), 13$ \\
\hline Eye disorders & $8(3.0), 12$ & $4(2.0), 4$ & $3(3.7), 6$ & $5(1.8), 8$ \\
\hline Eye irritation & $2(0.7), 6$ & $1(0.5), 1$ & $1(1.2), 4$ & $2(0.7), 5$ \\
\hline Eye swelling & $3(1.1), 3$ & $1(0.5), 1$ & - & $1(0.4), 1$ \\
\hline Eyelid oedema & $2(0.7), 2$ & $2(1.0), 2$ & $2(2.5), 2$ & $2(0.7), 2$ \\
\hline Gastrointestinal disorders & $6(2.2), 8$ & $1(0.5), 1$ & 12 (14.8), 73 & 13 (4.8), 74 \\
\hline Glossodynia & $1(0.4), 1$ & - & $2(2.5), 3$ & $2(0.7), 3$ \\
\hline Lip pruritus & - & - & $2(2.5), 8$ & $2(0.7), 8$ \\
\hline Lip swelling & - & - & $3(3.7), 5$ & $3(1.1), 5$ \\
\hline Oedema mouth & - & - & $2(2.5), 8$ & $2(0.7), 8$ \\
\hline Oral discomfort & - & - & $2(2.5), 4$ & $2(0.7), 4$ \\
\hline Oral pruritus & $1(0.4), 1$ & $1(0.5), 1$ & $5(6.2), 11$ & $6(2.2), 12$ \\
\hline Paraesthesia oral & $1(0.4), 1$ & - & $4(4.9), 12$ & $4(1.5), 12$ \\
\hline Tongue pruritus & - & - & $4(4.9), 8$ & $4(1.5), 8$ \\
\hline General disorders and administration site conditions & 48 (17.7), 221 & $40(20.2), 222$ & 10 (12.3), 48 & $46(17.0), 242$ \\
\hline Fatigue & $6(2.2), 41$ & $3(1.5), 28$ & $2(2.5), 11$ & $5(1.8), 39$ \\
\hline Feeling hot & $3(1.1), 6$ & $3(1.5), 8$ & $2(2.5), 8$ & $4(1.5), 10$ \\
\hline Injection site erythema & $3(1.1), 5$ & $4(2.0), 5$ & - & $4(1.5), 5$ \\
\hline Injection site pain & $5(1.8), 6$ & $8(4.0), 10$ & $1(1.2), 1$ & $8(3.0), 10$ \\
\hline Injection site pruritus & $13(4.8), 40$ & $8(4.0), 29$ & $1(1.2), 1$ & $9(3.3), 30$ \\
\hline Injection site swelling & $6(2.2), 14$ & $6(3.0), 11$ & - & $6(2.2), 11$ \\
\hline Injection site warmth & $2(0.7), 3$ & $3(1.5), 7$ & $1(1.2), 3$ & $3(1.1), 7$ \\
\hline Local swelling & $16(5.9), 35$ & 15 (7.6), 46 & $2(2.5), 12$ & $15(5.5), 46$ \\
\hline Oedema peripheral & $9(3.3), 38$ & $8(4.0), 38$ & $2(2.5), 3$ & $10(3.7), 41$ \\
\hline Pain & $5(1.8), 7$ & $5(2.5), 7$ & $1(1.2), 1$ & $5(1.8), 7$ \\
\hline Swelling & $8(3.0), 12$ & $7(3.5), 18$ & $4(4.9), 7$ & $9(3.3), 21$ \\
\hline Immune system disorders & $5(1.8), 5$ & $3(1.5), 3$ & $2(2.5), 2$ & $3(1.1), 3$ \\
\hline Anaphylactic reaction & $4(1.5), 4$ & $3(1.5), 3$ & $2(2.5), 2$ & $3(1.1), 3$ \\
\hline Infections and infestations & $2(0.7), 5$ & $1(0.5), 2$ & $2(2.5), 6$ & $3(1.1), 8$ \\
\hline Nasopharyngitis & $2(0.7), 5$ & $1(0.5), 1$ & $1(1.2), 4$ & $2(0.7), 5$ \\
\hline Musculoskeletal and connective tissue disorders & $7(2.6), 12$ & $4(2.0), 6$ & $1(1.2), 5$ & $5(1.8), 11$ \\
\hline Pain in extremity & $5(1.8), 9$ & $3(1.5), 4$ & $1(1.2), 5$ & $4(1.5), 9$ \\
\hline Nervous system disorders & $5(1.8), 10$ & $2(1.0), 3$ & $4(4.9), 7$ & $6(2.2), 10$ \\
\hline Dizziness & $3(1.1), 3$ & $1(0.5), 1$ & - & $1(0.4), 1$ \\
\hline Headache & $2(0.7), 5$ & - & $2(2.5), 5$ & $2(0.7), 5$ \\
\hline Respiratory, thoracic and mediastinal disorders & $16(5.9), 48$ & $11(5.6), 21$ & $16(19.8), 42$ & $25(9.2), 57$ \\
\hline Cough & $3(1.1), 12$ & $3(1.5), 3$ & $3(3.7), 6$ & $6(2.2), 9$ \\
\hline Dyspnoea & $5(1.8), 12$ & $5(2.5), 6$ & $3(3.7), 4$ & $6(2.2), 7$ \\
\hline Nasal congestion & $3(1.1), 3$ & $2(1.0), 2$ & $2(2.5), 2$ & $3(1.1), 3$ \\
\hline Pharyngeal oedema & $3(1.1), 3$ & $1(0.5), 1$ & $2(2.5), 2$ & $3(1.1), 3$ \\
\hline Rhinorrhoea & $2(0.7), 5$ & $2(1.0), 5$ & - & $2(0.7), 5$ \\
\hline Sneezing & $4(1.5), 6$ & $2(1.0), 2$ & $2(2.5), 4$ & $4(1.5), 6$ \\
\hline Throat irritation & $1(0.4), 1$ & - & 7 (8.6), 19 & $7(2.6), 19$ \\
\hline Skin and subcutaneous disorders & 33 (12.2), 105 & $28(14.1), 94$ & 7 (8.6), 28 & 32 (11.8), 103 \\
\hline Erythema & 12 (4.4), 23 & $8(4.0), 26$ & $3(3.7), 12$ & $10(3.7), 29$ \\
\hline
\end{tabular}


Table 5 continued

\begin{tabular}{lllll}
\hline $\begin{array}{l}\text { MedDRA system organ class } \\
\text { MedDRA preferred term }\end{array}$ & $\begin{array}{l}\text { Primary SCIT } \\
n(\%), \mathrm{E}\end{array}$ & $\begin{array}{l}\text { Concomitant SCIT } \\
n(\%), \mathrm{E}\end{array}$ & $\begin{array}{l}\text { Concomitant SLIT } \\
n(\%), \mathrm{E}\end{array}$ & $\begin{array}{l}\text { Concomitant AIT } \\
n(\%), \mathrm{E}\end{array}$ \\
\hline Pruritus & $20(7.4), 67$ & $15(7.6), 46$ & $2(2.5), 10$ & $16(5.9), 51$ \\
Hyperhidrosis & $1(0.4), 1$ & $1(0.5), 1$ & $1(1.2), 1$ & $2(0.7), 2$ \\
Rash & $7(2.6), 7$ & $7(3.5), 7$ & $2(2.5), 2$ & $7(2.6), 7$ \\
Urticaria & $3(1.1), 4$ & $5(2.5), 10$ & $1(1.2), 2$ & $5(1.8), 10$ \\
\hline
\end{tabular}

AIT allergy immunotherapy, $E$ number of events, MedDRA Medical Dictionary of Drug Regulatory Activities, SCIT subcutaneous immunotherapy, SLIT sublingual immunotherapy

${ }^{\text {a }}$ Including eight patients with combinations of SCIT and SLIT

investigator bias. Physicians were instructed to include patients in a consecutive order to reduce a potential selection bias. By evaluating 271 patients who received a concomitant AIT treatment and for which data on safety and tolerability were recorded ADRs with an incidence of $2 \%$ with a probability of $95 \%$ can be detected at least once. This only allows the comparison of ADRs with data from previous studies of similar design that have included primarily patients treated with one single allergen product in terms of frequency of ADRs, and safety and tolerability profiles for those ADRs that have been identified to occur with the highest frequency for the primary SCIT. The duration of our study was short compared with the 3-year treatment term that is recommended for a complete AIT treatment.

\section{Conclusions}

In conclusion, frequency of ADRs was not considerably increased in the present study compared with data from a previous large non-interventional study with a low proportion of patients who received a concomitant AIT, and no change in the tolerability profile was observed when SCIT $\left(\mathrm{AVANZ}^{\circledR}\right.$ ) was administered with concomitant SCIT or SLIT.

Acknowledgements We would like to thank all the physicians who participated in the study.

\section{Compliance with Ethical Standards}

Funding The study was funded by ALK.

Conflict of interest Rainer Reiber received remuneration from ALK for the documentation of patient data from his practice for this study, financial support for attending symposia and for reviewing the manuscript. Jörg Schnitker was funded by ALK as Clinical Research Organization in the study. Hendrik Wolf and Eike Wüstenberg are employees of ALK and hold stock options.

Ethical approval The study was approved by the Ethics Committee of the Landesärztekammer Baden-Württemberg (Reference N. F-2012-043).
Study registration DRKS DRKS00005030. Registered 28 May 2013, retrospectively registered.

Informed consent Patient consent for collection of their data was obtained.

Previous publication Data from this article were published in abstract form in Reiber R, Wolf H, Schnitker J, Wüstenberg E. SCIT with an immunologically enhanced subcutaneous immunotherapy preparation is well tolerated in patients concomitantly treated with further allergy immunotherapy. Allergy 2016;71 (Suppl. 102):509 (Poster presentation at the European Academy of Allergy and Clinical Immunology Congress, 11 to 15 June 2016, Vienna, Austria).

Open Access This article is distributed under the terms of the Creative Commons Attribution-NonCommercial 4.0 International License (http://creativecommons.org/licenses/by-nc/4.0/), which permits any noncommercial use, distribution, and reproduction in any medium, provided you give appropriate credit to the original author(s) and the source, provide a link to the Creative Commons license, and indicate if changes were made.

\section{References}

1. Bousquet PJ, Castelli C, Daures JP, Heinrich J, Hooper R, Sunyer $\mathrm{J}$, Wjst M, Jarvis D, Burney P. Assessment of allergen sensitization in a general population-based survey (European Community Respiratory Health Survey I). Ann Epidemiol. 2010;20:797-803.

2. Passalacqua G. The use of single versus multiple antigens in specific allergen immunotherapy for allergic rhinitis: review of the evidence. Curr Opin Allergy Clin Immunol. 2014;14:20-4.

3. Calderon MA, Cox L, Casale T, Moingeon P, Demoly P. Multiple-allergen and single allergen strategies in poly-sensitized patients: looking at the published evidence. J Allergy Clin Immunol. 2012;129:929-34.

4. Barth C, Anero F, Pfaar O, Klimek L, Hörmann K, Stuck BA. Safety aspects of subcutaneous immunotherapy with multiple allergens - a retrospective analysis on polysensitized patients. Eur Arch Otorhinolaryngol. 2010;267:1873-9.

5. Reiber R, Keller M, Keller W, Wolf H, Schnitker J, Wüstenberg E. Tolerability of the SQ-standardised grass sublingual immunotherapy tablet in patients treated with concomitant allergy immunotherapy: a non-interventional observational study. Clin Transl Allergy. 2016;6:9. doi:10.1186/s13601-016-0097-8.

6. Pfaar O, Jung K, Wolf H, Decot E, Kleine-Tebbe J, Klimek L, Wüstenberg E. Immunological effects and tolerability of a new fast updosed immunologically enhanced subcutaneous 
immunotherapy formulation with optimized allergen/adjuvant ratio. Allergy. 2012;67:630-7.

7. Kleine-Tebbe J, Walmar M, Bitsch-Jensen K, Decot E, Pfaar O, Hernández Fernández de Rojas D, Rodriguez F. Negative clinical results from a randomised, double-blind, placebo-controlled trial evaluating the efficacy of two doses of immunologically enhanced, grass subcutaneous immunotherapy despite dose-dependent immunological response. Clin Drug Investig. 2014;34:577-86.

8. Moreno C, De San Pedro BS, Millán C, Panizo C, Martín S, Florido F. Exploratory study of tolerability and immunological effect of a short up-dosing immunotherapy phase with a standardised allergen extract derived from pollen of Olea europaea. Clin Transl Allergy. 2015;5:27. doi:10.1186/s13601-015-0070-y.

9. Sastre J, Rodriguez F, Campo P, Laffond E, Marin A, Alonso MD. Adverse reactions to immunotherapy are associated with different patterns of sensitization to grass allergens. Allergy. 2015;70:598-600.
10. EMEA. Guideline on the clinical development on products for specific immunotherapy for the treatment of allergic diseases. 2008 Jun 1. Report No.: CHMP/EWP/18504/2006.

11. Directive 2001/20/EC of the European parliament and the council of April 42001 on the approximation of the laws, regulations and administrative provisions of the Member States relating to the implementation of good clinical practice in the conduct of clinical trials on medicinal products for human use. Official Journal of the European communities 1.05.2001, L121: 34-44.o.: CHMP/EWP/ $18504 / 2006$.

12. AVANZ ${ }^{\circledR}$ [summary of product characteristics]. Hamburg: ALK; dated June 2014.

13. Hauswald B, Wolf H, Becker F, Becker S, Schnitker J, Wüstenberg E. Tolerability of a new fast updosed immunologically enhanced subcutaneous immunotherapy formulation with an optimized allergen to adjuvant ratio under routine practice conditions: a noninterventional observational study. J Investig Allergol Clin Immunol. 2013;23:471-7. 